\title{
Avaliação da capacidade de reconhecimento de erros de português escrito em pós-ǵraduandos em oftalmologia
}

\author{
Assesment of the ability to recognize written Portuguese mistakes by postgraduation \\ students in Ophthalmology
}

Carlos Alberto Rodrig'ues-Alves ${ }^{1}$

${ }^{1}$ Professor Associado e Chefe do Serviço de NeuroOftalmologia do Departamento de Oftalmologia e Otorrinolaringologia Faculdade de Medicina Universidade de São Paulo - USP. Coordenador do Curso de Pós-Graduação em Oftalmologia da Universidade de São Paulo - USP

Endereço para correspondência: Rua Prof. Artur Ramos, $183-8^{\circ}$ andar - São Paulo (SP) CEP 01454-011

Recebido para publicação em 22.10.01 Aceito para publicação em 08.05.2002

Nota Editorial: Pela análise deste trabalho e por sua anuência na divulgação desta nota, agradecemos ao Dr. Carlos Ramos de Souza-Dias.

\section{RESUMO}

Objetivo: Avaliar a capacidade de pós-graduandos em oftalmologia para corrigir erros de português contidos em sentenças. Métodos: Solicitou-se a correção de erros encontrados em 18 frases fictícias. Resultados: 30 alunos responderam os testes e cometeram 92 erros. O número médio de erros por aluno foi de 3,066. 26,66\% dos examinados cometeram 5 ou mais erros. Conclusão: Um quarto dos alunos de pós-graduação em Oftalmologia avaliados demonstrou resultados sofríveis quanto à correção de textos escritos em português.

Descritores: Linguagem; Redação; Comportamento verbal; Escrita manual; Testes de linguagem; Educação de pós-graduação em Medicina, Oftalmologia

\section{INTRODUÇ̃̃̃O}

A tão longa convivência com Cursos de Pós-Graduação, e com tudo aí contido, tem mostrado pouco conhecimento da nossa língua por parte dos pós-graduandos. É comum o achado de português precário, inexato, deselegante e inaceitável para futuros professores universitários. Este fato foi bem comentado, aliás, por Souza- Dias, no Editorial -3 dos ABO em 1996 ${ }^{(1)}$. Esse autor discute alguns dos diversos erros e imprecisões corriqueiras nos textos e discursos médicos.

\section{OBJETIVO}

Para se obter amostragem do português escrito por grupo de pósgraduandos em oftalmologia foi realizada esta pesquisa. Atentou-se, de modo particular mas não exclusivo, para a concordância verbal.

\section{MÉTODOS}

Sem que os indivíduos soubessem previamente do teste, solicitou-se aos 30 alunos do curso de Pós-Graduação da Oftalmologia da USP, matriculados na Disciplina "Metodologia Científica" em 2001, a correção dos erros eventuais contidos nas 18 frases fictícias relacionadas abaixo. Quando o participante não corrigia a falta do texto, considerava-se erro do aluno.

1 - Duvidou-se das conclusões da pesquisa.

2 - Avaliou-se as conclusões da pesquisa.

3 - Restringiu-se os gastos com a bolsa 
4 - Protege-se os reagentes químicos dos fungos

5 - Protege-se dos fungos os reagentes químicos

6- Protegeu-se dos fungos os reagentes químicos

7 - A escola, onde se da cursos de primeiro grão, deve mudar

8 - Descreveu-se nos estados europeus diversos casos de doença da vaca louca.

9 - Existe, segundo o Secretário da Saúde, cinco eventos de raiva anualmente no Estado de São Paulo.

10 - O processo esclareceu de que o gerenciamento da esta tal estava irregular.

11 - Se você pôr o reagente, poderá ser encontrada a resposta.

12 - Uma enzima foi encontrada no vírus.

13 - A investigação será reaberta se houverem novos casos de dengue.

14 - Ainda está sobrando muitos tubos de ensaio.

15 - Naquela época não se fundia ferro e bronze.

16 - Com o oftalmoscópio direto não se viu corpos flutuantes de vítreo.

17 - Passado 4 anos não se constatou metástases na ressonância.

18 - Já chegou informações segundo as quais se perdeu os reagentes químicos necessários a reação química.

\section{RESULTADOS}

Apresentados na Tabela 1.

\begin{tabular}{|c|c|}
\hline No. de erros por aluno & No. de alunos \\
\hline 0 & 5 \\
\hline 1 & 3 \\
\hline 2 & 4 \\
\hline 3 & 7 \\
\hline 4 & 3 \\
\hline 5 & 2 \\
\hline 6 & 2 \\
\hline 7 & 2 \\
\hline 8 & 0 \\
\hline 9 & 1 \\
\hline 10 & 1 \\
\hline \multicolumn{2}{|l|}{ Total de Erros = 92} \\
\hline \multicolumn{2}{|l|}{ Total de alunos $=30$} \\
\hline \multicolumn{2}{|c|}{ № médio de erros por aluno $=3,066$} \\
\hline
\end{tabular}

\section{DISCUSSÃO}

Embora pequena, esta amostragem demonstra alguns dados de interesse. Na média o número de erros por aluno foi: 3,066 . Entretanto, oito alunos cometeram 5 ou mais erros. Isto compreende $26,66 \%$ da casuística. É bastante provável que, se o teste incluísse outros aspectos da língua, curiosas informações pudessem ser obtidas. Com isso, estaríamos mais bem esclarecidos sobre o nível de qualificação de pós-graduandos na redação e verbalização de textos em português. Este tipo de pesquisa forneceria, portanto, subsídios para eventuais providências quanto a melhoramentos no ensino da nossa língua.

\section{CONCLUSÕES}

O trabalho demonstra a apenas regular formação em português escrito de grupo de pós-graduandos em Área Médica. Como conseqüência, fica a sugestão para que aferições mais amplas sejam efetuadas neste campo.

Maior cuidado deve ser dado aos universitários para melhorar o português que eles falam e escrevem.

\section{ABSTRACT}

Purpose: To evaluate the skills of postgraduation students of São Paulo University to correct Portuguese errors contained in given sentences. Methods: The students were asked to make corrections in 18 fictitious sentences. Results: 30 students answered the test, having made 92 mistakes. The average number of mistakes made per student was 3.066. Conclusion: One quarter of the students presented poor results in the correction of written Portuguese texts.

Keywords: Writing; Language; Verbal behavior; Handwriting; Language tests; Undergraduate education medical; Ophthalmology

\section{REFERÊNCIAS}

1. Souza-Dias CR. Desrespeito ao vernáculo. Arq Bras Oftalmol 1996;59:343-4.

\section{ABO ELETRÔNICO}

Novo site

Acesso: http://www.abonet.com.br 